\title{
A DISPERSÃO DA IDENTIDADE AUTORAL NO CIBERESPAÇO: ZIRALDO, HERÓI E VILÃO DO ORKUT
}

\author{
Edgar Roberto Kirchof \\ Universidade Luterana do Brasil (ULBRA/RS/Canoas) \\ ekirchof@hotmail.com \\ Carlos Augusto Falcão Filho \\ Universidade Luterana do Brasil (ULBRA/RS/Torres) \\ dudawfalcao@hotmail.com
}

O presente artigo pretende discutir o modo como são construídas diferentes representações em torno da identidade do autor literário a partir da ciberesfera, mais especificamente, no Orkut, tomando como objeto de análise o escritor de livros infantis Ziraldo. Ao pesquisar o seu nome no Google, encontram-se aproximadamente 447.000 referências, entre sites e blogs que discutem e divulgam o autor e sua obra. Somente no Orkut, são aproximadamente 60 comunidades que o exaltam ou, então, questionam sua integridade ética bem como a qualidade de suas obras.

Dentro desse universo, propõe-se, como recorte deste estudo, a representação da identidade autoral de Ziraldo em um espaço específico dentro da internet, a saber, a comunidade Ziraldo Fan, no Orkut, disponível no seguinte endereço: http://www.orkut.com.br/Main\#Community?cmm=60906. O critério de seleção dessa comunidade levou em conta o maior número de usuários cadastrados com postagens recentes dos tópicos, indicando atividades atualizadas. Ziraldo Fan é a primeira comunidade on-line feita em homenagem ao escritor e possui 4.159 membros. Assim como outras comunidades semelhantes, trata-se de um espaço público gerenciado por pessoas que possuem perfis no Orkut. Elas definem a

\section{(c) $(\mathbb{D} \otimes \Theta$}

Texto Digital, Florianópolis, v. 7, n. 2, jul./dez. 2011. ISSNe: 1807-9288 
própria identidade desses usuários e, também, a partir de suas discussões, constroem diferentes a(s) identidade(s) para o autor Ziraldo.

As reflexões aqui propostas sobre a questão da identidade autoral estão alinhadas com a perspectiva dos Estudos Culturais - representados, entre outros, por Stuart Hall, Kathryn Woodward, Antonio Flávio Barbosa Moreira, Tomaz Tadeu da Silva. Também serão utilizados, como aporte, os estudos de Roger Chartier e Michel Foucault sobre a história da leitura e da autoria, numa perspectiva que leva em conta as transformações dos suportes. Assim sendo, a ênfase será colocada sobre o aspecto historicamente "produzido" ou "construído" da identidade autoral, uma vez que esta se encontra diretamente vinculada às relações que estabelece com diferentes suportes de escrita bem como com as representações culturais que se criam, historicamente, em torno de tais suportes. Nessa perspectiva, não existe identidade, mas identidades de autor, que vão sendo construídas, reconstruídas e deslocadas ao longo da história, juntamente com a produção, a reconfiguração e as constantes mutações pelas quais passam os suportes de escrita.

\section{Identidade(s) de autor: a perspectiva dos Estudos Culturais}

Para entender o vínculo entre autoria e identidade, é importante refletir inicialmente sobre o conceito de representação. De acordo com Stuart Hall (1997), representação é a prática central que produz a cultura. A cultura, por sua vez, pode ser compreendida a partir dos significados partilhados produzidos a partir da linguagem. A linguagem nos permite, portanto, conferir sentido às coisas. Dessa forma, cultura, significados partilhados, sentidos produzidos e linguagem fazem parte de um mesmo sistema de representação, que utiliza os signos como veículos, dentre os quais podemos citar as palavras escritas, os sons, as imagens, entre tantas outras possibilidades. 
A hipótese em favor da qual se pretende argumentar aqui, com o auxílio dos estudos realizados por Roger Chartier (entre outros, 1998, 2001, 2002), é a seguinte: quando as representações em torno de um autor literário são deslocadas de um suporte para outro, ocorrem deslocamentos de sentido quanto à identidade do autor. Nas palavras de Chartier (2001, p. 43), "uma realidade textual não deve ser entendida unicamente em sua dimensão literária, pois também arraiga-se profundamente em sua realidade material, que é a forma do livro em que se abarcava o texto". Práticas culturais de produção e de consumo de representações e identidades se regulam, portanto, também a partir dos significados instaurados em torno de diferentes suportes de leitura.

Em outros termos, as relações sociais de produção e consumo da escrita transformam a identidade do autor, ao longo da história, bem como as demais instâncias envolvidas no circuito da produção e do consumo da escrita literária, sendo que um dos fatores envolvidos nesse processo é a constante transformação a que são submetidos os suportes de leitura. E se tal fenômeno ocorre é porque, de acordo com Stuart Hall (1977), não é o objeto em si mesmo que possui significado. São os participantes de cada cultura que conferem significância às pessoas, objetos e eventos. Por isso, os significados, seja de livros ou de autores, não são fixos, únicos ou estáveis, podendo mudar ao longo do tempo e do espaço em que se inserem.

Como nos informa Roger Chartier (1988), na Grécia Antiga, por exemplo, escreviam-se textos em rolo. Quando o códice ${ }^{1}$ surge, ocorrem inovações não apenas em relação à materialidade desse novo suporte, mas também e principalmente em relação à representação cultural da escrita e da própria autoria. Ao contrário do rolo, o códice era mais econômico, pois comportava a escrita dos dois lados da folha e aumentava a capacidade de informações contidas no objeto.

\footnotetext{
${ }^{1} \mathrm{Na}$ origem, designava as tabuinhas enceradas sobre as quais se escrevia. Posteriormente, entrando em circulação o pergaminho e o papel, o vocábulo continuou a ser empregado, como sinônimo de manuscrito cujas folhas se dispunham na forma dos livros atuais. Nos dias que correm, aplica-se o termo de preferência aos textos anteriores à invenção da imprensa (Moisés, 2004).
} 
Pode ser aberto em qualquer página, facilitando o manuseio. O rolo, por sua vez, precisava ser desenrolado para se chegar a um trecho específico e, depois, enrolado e desenrolado sucessivamente para que o leitor atingisse as informações que procurava. Sendo mais prático de manusear, o códice se disseminou rapidamente na sociedade antiga através dos primeiros livreiros romanos. A partir disso, projetou-se um comércio em torno do livro, cujo impacto sobre a representação cultural da escrita e da identidade de autor continua sendo objeto de estudos até hoje.

Durante a Idade Média, na Europa, o códice foi amplamente utilizado pelos monges copistas. Porém, houve, ao contrário do que acontecia na Roma Antiga, uma retração no seu comércio, já que a Igreja Católica tornou-se detentora da produção e preservação dos livros. Os mosteiros transformaram-se nos centros de arquivamento da memória da cultura antiga. Guardar as escrituras sagradas justificava sua importância naquela sociedade eclesiástica. Havia regras para a produção de livros relacionadas com a escrita, a decoração e a encadernação. Em um único códice, podia-se armazenar toda a bíblia, por exemplo. Os monges, ao copiarem livros, acreditavam estar a serviço de Deus. Os mosteiros, por essa razão, tornam-se depósitos de saber, da cultura do passado e das ideias dos grandes filósofos.

Com o surgimento da imprensa de Gutenberg, no século XVI, o poder da Igreja Católica é abalado. Esta perde sua hegemonia, pois deixa de ser a detentora da produção e da preservação de livros, o que acarretou uma série de transformações culturais em torno da concepção da escrita bem como de todas as identidades que gravitam em torno dessa prática, especialmente em torno do nome do autor. Se, antes, as ideias valiam mais do que o nome que assina 0 documento em que elas estão representadas, a partir do século XVI, o nome do autor adquire uma relevância cada vez maior, cujo auge será atingido no século XVIII, conforme, entre outros, as reflexões de Foucault (2006) em torno da autoria. 
Como se percebe, na medida em que o suporte da escrita passa por algum processo de mudança em sua materialidade - por exemplo, deslocando-se de um suporte impresso para um suporte digital - pode-se supor que tais modificações afetam também a categoria do próprio autor enquanto uma identidade cultural. Segundo Chartier (1999), estamos vivendo, a partir da internet, um momento sem mediações, ou seja, não há necessidade, em um blog ou em site criado por um autor, de que exista um censor, ou alguém que vá definir externamente o que deve ou não ser escrito. Da mesma forma, qualquer pessoa pode assumir a função de refletir sobre as obras, anteriormente reservada ao crítico literário, na medida em que a internet permite que se publique todo tipo de reflexão, opinião, crítica ou elogio em relação a qualquer autor.

No caso específico do Orkut, Rosa Maria Hessel Silveira (2006) nos alerta que suas comunidades atuam como rótulos ou vitrines virtuais em que é possível, por um lado, exibir identidades e, por outro, espiar silenciosamente - e sem ser percebido - aqueles que nos instigam curiosidade. Ao mesmo tempo, esse ambiente estimula a criação de representações dicotômicas em torno dos mais diversos assuntos, pois, na maioria dos casos, os internautas se posicionam de forma dicotômica quando são instigados a opinarem sobre algum tema.

No âmbito da Crítica Literária, a identidade de Ziraldo é representada normalmente enquanto autor legitimado dentro do cânone literário brasileiro endereçado para o público infantil, sendo que um dos traços mais destacados pelos críticos é sua originalidade quanto ao tratamento da linguagem visual, hibridada com a linguagem verbal (entre outros, Coelho: 1987; Lajolo \& Zilberman: 2002). No entanto, na medida em que se desloca para o ciberespaço, essa identidade passa a ser tensionada. Como se verá nas análises a seguir, no Orkut, a representação de Ziraldo adquire uma dimensão maniqueísta, pois a maior parte dos internautas se situa em grupos que se dividem em lados opostos: o primeiro grupo não apenas defende Ziraldo, mas o idolatra como um grande herói; o outro, 
por sua vez, ataca-o como se fosse um vilão, responsável por atos desprezíveis e grosseiros.

\section{Ziraldo idolatrado}

Nos discursos que idolatram Ziraldo, chama atenção, inicialmente, a reiteração de suas habilidades enquanto um grande artista e um grande escritor. Nas postagens, encontramos depoimentos eufóricos dos leitores sobre a maneira como enxergam, idealizam e constroem a identidade de "grande artista" para Ziraldo, como no exemplo abaixo:

um dos nossos melhores cartunistas. Um cara batalhador que com as publicações Pasquim, pasquim21, Bundas e a belíssima Palavra nos mostrou muito da historia desse país. Espero que seus cartuns inteligentes e personagens maravilhosos venham a ser publicados em livro de capa dura e papel brilhante para que possamos curtir mais. ${ }^{2}$

Conforme o membro da comunidade, Ziraldo é o melhor; é um batalhador. A postagem alude ao fato de que Ziraldo não estaria envolvido somente com a criação artística, mas também com o universo da sociedade e da cultura brasileira, reforçando a imagem de um Ziraldo representante do que nossa cultura possui de melhor e mais nobre.

A maior parte dos elogios, por sua vez, dirige-se aos seus livros, como se observa no excerto abaixo:

Sem dúvida é um dos livros infantis mais bonitos [...] no final da história quando os dois amigos já estão grandes, o menino cor-derosa mandou uma carta pro menino marrom dizendo que ele estava muito feliz pq descobriu que o branco era, somente, a ausência do preto. Sempre choro quando leio essa parte.

2 Todas as citações utilizadas aqui provêm da comunidade Ziraldo Fan (http://www.orkut.com.br/Main\#Community?cmm=60906) e foram acessadas em 08 de abril de 2011. Destaque-se que foi preservada a linguagem original utilizada pelos autores, sem qualquer adaptação para o português padrão.

Texto Digital, Florianópolis, v. 7, n. 2, jul./dez. 2011. ISSNe: 1807-9288 
Encontramos também depoimentos de pessoas que se identificam como amigos e familiares. Entre estes, um deles inicia com o título: O que dizer do Ziraldo?, conforme o texto abaixo:

Ziraldo um grande cara, inteligente, companheiro, iluminado mesmo por Deus, guerreiro e um grande amigo. nossa, escrevendo isso me lembro de uma foto que tenho com ele e a nossa turma... os dois ainda moleques.. bem diferente de hj! mas quero deixar aki a minha simples homenagem a esse tb gênio da criatividade e dos pinceis.

Outro depoimento que exalta as qualidades de Ziraldo, realizado por um dos membros da comunidade, é o seguinte:

1 - Ele é um artista único, tem sua própria personalidade artística, seus traços são incomparáveis e sua percepção de mundo é grandiosa. 2- Pelo fato de ele ser daqui, ser brasileiro, ser fruto desse país, nós devemos agradecer por ter mestres como ele...é isso aí....abraços; [...]

O membro da comunidade considera Ziraldo um artista único, não apenas por suas qualidades artísticas, mas também pelo fato de saber interpretar o mundo, representando-o através de sua arte. E, mais do que isso, o membro se identifica com o próprio autor por dividir com ele a mesma nacionalidade.

Também podem ser lidas manifestações ainda mais eufóricas, tais como "Ziraldo para presidente" ou "Ziraldo para ministro da educação". Observa-se que, para os fãs, não há limites quanto às habilidades de Ziraldo. $O$ autor que eles idolatram seria, em sua perspectiva, capaz de ocupar qualquer espaço para além da arte e da literatura, inclusive cargos políticos de extrema importância, com a mesma competência demonstrada na produção dos seus livros. 
Dentro dessa mesma visão, Ziraldo também é representado, pelos fãs, como um grande educador, cuja competência na área da Educação estaria legitimada pela capacidade já demonstrada para representar a cultura brasileira através de sua arte. No seguinte depoimento, um dos sujeitos pertencentes à comunidade intitula sua postagem de "Faz parte da minha vida". Trata-se de uma professora:

Durante muito tempo trabalhei como professora de Pré-escolar, e os livros que mais gostava de apresentar aos meus pequenos eram os livros do Ziraldo. Tenho uma enorme admiração por ele, mesmo quando os livros eram para crianças maiores eu os adaptava contando as histórias de forma que eles curtiam e entendiam. É simplesmente o máximo.

Ziraldo é "o máximo", segundo o depoimento, e suas histórias podem ser adaptadas, de acordo com a professora, de maneira que contemplem diferentes idades em fase escolar. O depoimento de outra professora ressalta, de modo semelhante, o modo como o autor teria atuado sobre a sua infância e como constituiu seus primeiros passos de leitora:

Eu me lembro de ter escutado a história do Menino Maluquinho desde pequena... Me apaixonei quando pude lê-la pela primeira vez... Eu tinha uns 8 anos. Depois, em 1995, veio a Professora Muito Maluquinha, minha outra paixão. Acho que tamanha identificação se dá pelo fato de eu ter a mesma idade do Menino Maluquinho e por sentir-me a própria Professora Maluquinha, pois este livro foi escrito no ano em que cursava o $1^{\circ}$ Ano de Formação de Professoras... Chorei e choro sempre quando o leio. Como Professora Maluquinha, tenho a oportunidade de ver muitos Meninos Maluquinhos por aí, mas nada me tira da cabeça que esta obra é a autobiografia do próprio Ziraldo.

Chama atenção, no depoimento, que a professora escutava as histórias do Menino Maluquinho antes mesmo de saber ler, o que revela o quanto o personagem circula, socialmente, mesmo de forma oral, permitindo a adesão de receptores ainda não alfabetizados. Além disso, o depoimento também revela outra constante nos vários depoimentos da comunidade, a saber, a identificação 
dos leitores/navegadores com o próprio Ziraldo ou seus personagens: a professora se intitula "Professora Maluquinha".

De fato, em diversos depoimentos - e não apenas de professores -, os membros afirmam que as obras de Ziraldo estiveram presentes intensamente em sua infância e, inclusive, no processo de alfabetização, o que reforça a representação de Ziraldo como um educador. A seguir, podem ser lidos, em sequência, alguns depoimentos que revelam essa perspectiva: "Valeu Ziraldo por ter contribuído e estimulado um montão de moleques como eu a estudar se divertindo ao mesmo tempo". "Sou fã do Ziraldo desde uns cinco ou seis anos, época em que aprendi a ler". "Desde que aprendi a ler, ainda menino - época em que a gente lê uma sílaba depois da outra para descobrir que palavra está nos desafiando, é que sou fã do Ziraldo". "Tenho orgulho de dizer q fui alfabetizado por livros tão fascinantes q ainda leio até hj!".

Nas postagens, pode-se constatar que os leitores se identificam simultaneamente como fãs de Ziraldo e também como seus aprendizes. Afirmam gostar, em alguns casos amá-lo, por sua simplicidade, genialidade, espontaneidade, por ser "super engraçado", inteligente e um artista ímpar. Muitos dos leitores que se dizem alfabetizados pelos livros de Ziraldo, quando entraram em contato com suas obras, mencionam principalmente o Menino Maluquinho e Flicts, que estariam disponíveis nas bibliotecas de suas escolas.

Em relação à Educação, também encontramos, em uma das postagens feita por uma professora, uma chamada convocando os membros da comunidade para um projeto na educação infantil: "Bom dia Boa tarde e Boa noite a todos, estou aki pois estou fazendo um projeto para a feira cultural da escola onde dou aula sobre o Ziraldo e gostaria que pudessem me mandar ideias ou sugestões, de livros ou atividades que acham importantes". Na postagem seguinte, outra professora responde indicando temas e estratégias de aula que abordam a literatura infantil produzida por Ziraldo. Evoca o livro Menino Maluquinho para dizer que, a partir 
dele, realizara um projeto interdisciplinar na escola em que trabalha, tendo sido o projeto premiado pela prefeitura de sua cidade.

Outra representação constante dos discursos celebratórios ressalta a ligação entre a imagem de Ziraldo e a cultura brasileira. Por exemplo, um dos membros da comunidade realiza a seguinte convocação: "Vamos fazer uma campanha para que o Ziraldo faça o Poster e o mascote do Pan 2007, a ser realizado no RJ. Afinal, ninguém desenha melhor o Rio e o Brasil do que ele!". Ziraldo é visto por muitos fãs como aquele ilustrador que melhor representa o país nos traços de seus pincéis: aquele desenhista que conhece o próprio país, um exemplo de alguém que tem conhecimento sobre a nação.

Um dos membros da comunidade chega a criar um tópico intitulado "Homenagem a Ziraldo", também articulando a identidade do artista a uma espécie de representante da cultura brasileira, pois a postagem traz a letra do samba-enredo criada por uma escola de samba do Rio de Janeiro:

Amor hoje é dia de festa

Faço um convite colorido vem brincar

Do desejo à leitura, universo de ternura

A SuperMãe, o Maluquinho e o Saci

Vem de lá...

De Caratinga pro cenário mundial

Ziraldo o multimídia, dá samba na avenida

Nesse carnaval

Sua voz não se calou

Esse "A.I." não é pra mim

Jeremias nem ligou

A Turma do Pererê, a lua hoje tem cor

Que brilha nessa noite de esplendor

O mundo colorido

De um maluco genial

que amou, se deu, participou

Pintou, bordou, cresceu o o...

O seu Pasquim vive até hoje, é imortal

Aplauso, é gol, é show de bola, é nacional

Lá vem minha Vila

Texto Digital, Florianópolis, v. 7, n. 2, jul./dez. 2011. ISSNe: 1807-9288 
Trazendo a magia...do saber

Se ler é sonhar, aprender, viajar

Nessa viagem eu sou mais Nenê

O leitor, no final de sua postagem, afirma que os personagens citados - a Supermãe, o Maluquinho, o Saci, o Jeremias -, são tipicamente brasileiros, o que permite concluir que uma das identidades construídas em torno de Ziraldo, nesse espaço específico, é de um autor celebrado como um grande artista, de um lado, e, de outro lado, como um artista capaz de representar a cultura brasileira de forma exemplar, sendo que essa representação está bastante vinculada ao modo como a brasilidade é construída nos meios de comunicação voltados para grandes massas: uma cultura alegre e divertida que encontra, no futebol e no carnaval, o ápice de sua manifestação.

\section{Autor vilipendiado}

Em contrapartida aos discursos que celebram o nome do autor Ziraldo, há também, na mesma comunidade, aqueles que o vilipendiam, construindo, dessa forma, uma identidade dicotomicamente oposta à primeira. A polarização das discussões em torno da identidade de Ziraldo gera representações que lembram a velha disputa televisiva e novelesca entre heróis e vilões. De fato, muitas das discussões terminam com a exclusão de depoimentos e opiniões por parte dos moderadores, o que revela que se trata de um espaço em que os discursos estão sob um controle explícito, cuja finalidade é a manutenção de representações celebratórias.

Por uma questão de delimitação, a seguir, serão apresentados apenas três assuntos polêmicos levantados na comunidade, a saber, primeiro, um livro de Ziraldo distribuído em uma rede de fast food; segundo, os pagamentos efetuados pelo governo como indenização a Jaguar e Ziraldo; terceiro, a entrevista que Ziraldo concede ao programa Amaury Júnior, na qual se posiciona contra a 
variação linguística comum ao ciberespaço, frequentemente denominada de internetês.

No primeiro tópico polêmico, um dos membros decide contestar a qualidade dos alimentos vendidos em um determinado estabelecimento de fast food, considerando-os "um veneno". O membro da comunidade critica Ziraldo por permitir que um dos seus livros seja dado como brinde por essa empresa. Ou seja, ao associar o brinde produzido por Ziraldo ao comércio, o leitor desconstrói o discurso celebrativo predominante na comunidade, ao instalar uma representação que coloca Ziraldo não como um educador idealista, mas como um sujeito movido por interesses próprios e aparentemente egoístas. O membro da comunidade escreve que ficou revoltado por ter acreditado que o trabalho de Ziraldo jamais se vincularia a determinada empresa. Achou que o livro fosse uma imitação, mas, em suas próprias palavras: "estava até assinado. Poxa vida essa eu não acreditei...".

A postagem seguinte desse tópico é a de um dos membros que sai em defesa do autor, afirmando que ele precisa receber pelo seu trabalho para ganhar a vida. $\mathrm{O}$ leitor afirma ser um defensor nada imparcial de Ziraldo. Ou seja, tudo o que for dito contra o autor será rebatido por esse membro da comunidade, invariavelmente. Novas postagens são feitas para dar corpo à defesa e, no final do tópico, encontra-se a mensagem de que algumas postagens foram removidas temporariamente. Dessa maneira, com a exclusão de novas postagens, o poder que os moderadores possuem sobre a comunidade acaba por regular, ou seja, controlar os discursos de tal maneira que a imagem de Ziraldo seja preservada e continue sendo celebrada.

Outro assunto polêmico trazido à tona é o recebimento de indenizações pagas pelo governo, devido à perseguição que Ziraldo sofrera durante a ditadura, ainda em 1964, resultando no cancelamento de sua revista Turma do Pererê e a ocorrência, nos tempos de repressão, durante dois meses, da prisão de Ziraldo, Jaguar e outros jornalistas do Pasquim. O membro da comunidade que institui 
essa polêmica intitula a sua postagem do seguinte modo: "Repúdio às imorais indenizações de Ziraldo e Jaguar". A discussão que se desencadeia, mais uma vez, é um debate entre aqueles que celebram a imagem do autor e aqueles que consideram suas ações incabíveis. Um dos comentários polêmicos sobre esse assunto, realizado por um dos membros da comunidade, é o seguinte:

Há que se registrar a cupidez vergonhosa de dois jornalistas do nível de Ziraldo e Jaguar, que encerram suas vidas profissionais desenhando em tinta marrom a charge da desmoralização de suas lutas e da degradação moral de suas biografias. Transformaram em negócio o que pensávamos ter sido feito por dignidade pessoal e bravura cívica. Receberam, por décadas, o nosso aplauso sincero. Agora, por dinheiro, escarnecem de toda a cidadania, chocada e atônita com a revelação de suas verdadeiras personalidades e intenções.

Em contrapartida, existem novamente os membros da comunidade que fazem a defesa de Ziraldo. Dentre as tantas postagens a seu favor, destaca-se a seguinte:

Ziraldo afirma que começou a ser perseguido pela ditadura ainda em 1964, cinco anos antes do Pasquim ser lançado, quando a edição de sua revista "Pererê", com tiragem igual as das revistas 'Luluzinha' e 'Bolinha', foi cancelada. Ao longo dos anos de chumbo, viria a ter mais prejuízos por conta de edições por ele criadas, que foram perseguidas até serem fechadas. O processo correu na justiça por dezenove anos. O julgamento da opinião pública foi bem mais rápido... Por fim, a Comissão de Anistia provavelmente chegou à conclusão que, aos 75 anos, Ziraldo teria conseguido uma aposentadoria superior a de 1.300 reais que ele diz ter hoje em dia, e decidiu reparar esse dano pagando-lhe 4 mil por mês. O Polêmico milhão, na verdade, são os atrasados dos ultimos 19 anos, e pode ser dividido em prestações mensais. Acho oportuno acrescentar, por conta própria, que uma bomba foi colocada na redação do Pasquim nos tempos da repressão, e que Ziraldo, Jaguar, e outros do jornal, chegaram a ficar 2 meses presos sem qualquer acusação formal. Espero ter contribuido, com essas informações, para o julgamento que a comunidade vem fazendo do 'réu'.

Percebe-se que os membros da comunidade instituem, quanto aos assuntos polêmicos que cercam Ziraldo, uma espécie de julgamento. As postagens indicam, 
inicialmente, comentários que atacam a integridade moral do autor, enquanto as seguintes o defendem, buscando absolvê-lo das acusações realizadas pelos próprios membros da comunidade. Nesse sentido, mesmo naqueles tópicos em que Ziraldo é vilipendiado, a voz de seus fãs o protege, fazendo prevalecer o discurso da celebração em detrimento do discurso da acusação. Certamente, o controle realizado pelos moderadores da comunidade desempenha um papel central na manutenção dos discursos de defesa, sendo que, para tanto, estes chegam a utilizar inclusive de ironia com o intuito de desqualificar os ataques à imagem de Ziraldo, o que pode ser percebido, entre outros, através da postagem abaixo:

\begin{abstract}
Acho engraçado ficarem de nhé nhé nhé por causa dessa indenização alcançada de forma legal enquanto o filho do vosso Presidente, é o filho do operário Cefalópode, vira fazendeiro, fecha contrato de milhões com firmas criadas do dia pra noite, etcétera... Mas o Cefalópode pode se endinheirar que nenhum brasileiro vai achar feio né? Hohohohohohohoho.
\end{abstract}

Quando não ironizam, logo o tópico recebe a seguinte mensagem: "Algumas respostas nesta página foram excluídas ou estão sob revisão". Dessa forma, os moderadores não permitem, aos leitores, que conheçam o teor de postagens que continuaram sendo feitas. O assunto é censurado, de forma que se preservem, novamente, apenas as representações celebratórias em torno da identidade de Ziraldo.

A última polêmica abordada aqui diz respeito a uma entrevista cedida por Ziraldo ao programa do entrevistador Amaury Júnior. A postagem de um dos membros da comunidade inicia com o seguinte título: "Também gosto dele, mas ele não gosta de nós...". O indivíduo que criou o tópico indica um link que remete para o youtube. Ao acessar o link, é possível assistir a entrevista concedida ao apresentador. 


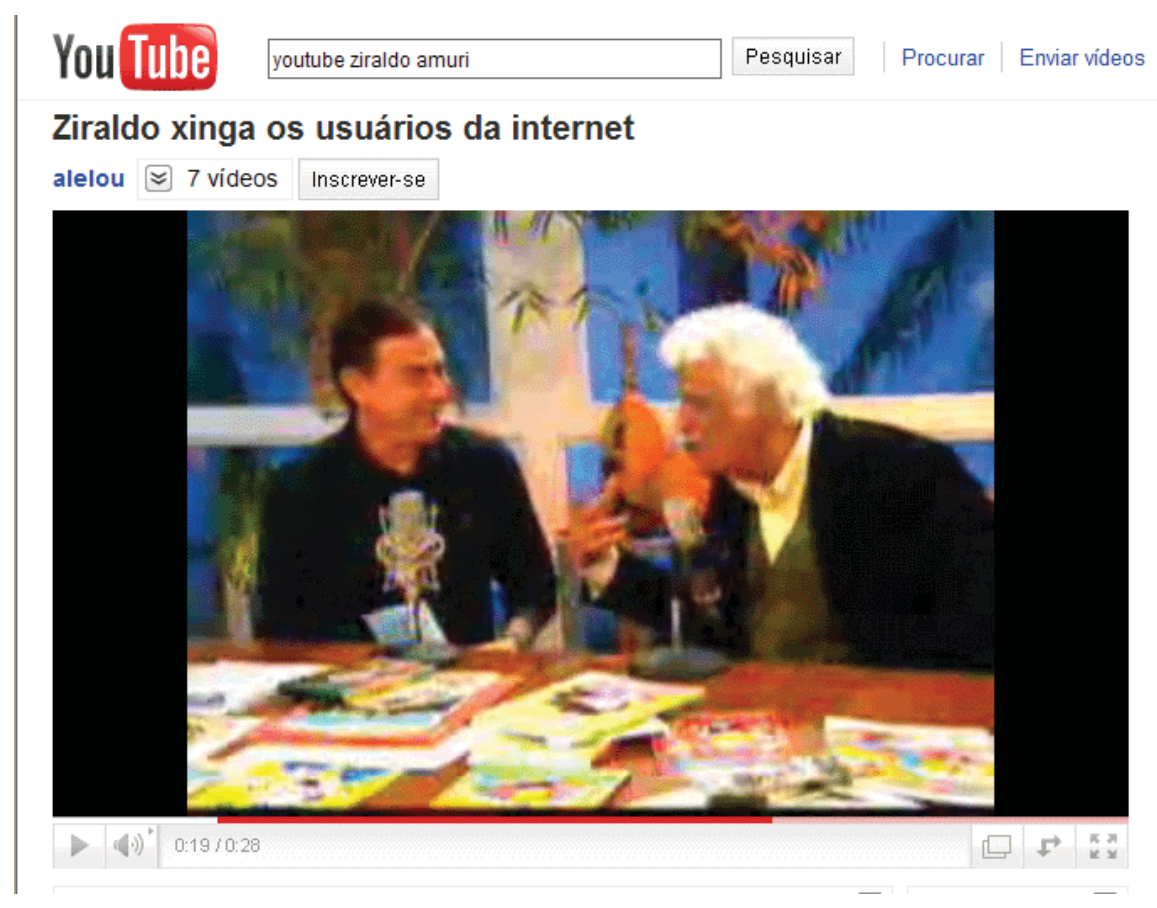

Figura 1: Ziraldo entrevistado por Amaury Jr., disponível em http://www.youtube.com/watch?v=gu-EK DTFGQ

Da entrevista, o membro da comunidade reproduz alguns enunciados de Ziraldo: "Tanto o celular quanto a Internet é o antro do débil mental. Só tem idiota na Internet. Usuário da Internet é um babaca. Começa a escrever tb no lugar de também, começa a escrever vc no lugar de você. Linguagem cifrada pra imbecil". Depois disso, o internauta faz uma espécie de alerta aos demais membros: "É só para vocês pararem de idolatrar alguém que chega a esse ponto". Assim como nos demais casos de acusação, novamente a defesa aparece de imediato, vinda de outro membro:

Gente, dá um tempo, se vocês se incluem no rol dos 'que escrevem tb em lugar de também', sintam-se ofendidos. Eu, sinceramente, não só não me sinto ofendida, como concordo com ele, plenamente. Ele falou sobre quem escreve internetês, não lê, nunca viu um livro na vida e tem cultura de google.

Apesar de se configurarem duas posições opostas, a discussão pende novamente para o lado que defende o autor. Mesmo que o discurso de Ziraldo sobre a variação linguística na internet deponha contra muitos dos seus fãs, membros 
dessa comunidade, a maioria continua dando razão ao autor, ou tentam explicar racionalmente os motivos que o levaram a dizer aquelas palavras, como por exemplo, nesta postagem:

Pessoal, na entrevista Ziraldo está indignado que o povo hoje em dia não presenteia um ao outro com um livro e que a tecnologia está deixando o pessoal analfabeto. E é verdade. Ele falou uma realidade - cruel, mas é o que está acontecendo. Ele não generalizou, mas podemos dizer que $80 \%$ dos internautas são o que ele disse! Eu concordo com ele.

É interessante notar que, não obstante as comunidades do Orkut buscarem manter a ordem dos discursos que circulam em seu interior restrita a uma perspectiva celebrativa, acabam por construir uma dupla representação para a identidade do autor Ziraldo, que poderia ser subsumida pela dicotomia entre herói e vilão. Assim sendo, é possível concluir que, embora haja um controle forte quanto à ordem dos discursos ali colocados em circulação, o Orkut acaba concedendo visibilidade também para discursos discordantes.

Por outro lado, o modo como o poder de controle dos discursos é exercido pelos moderadores faz com que mesmo os discursos subversivos acabem servindo para idolatrar o nome de Ziraldo, uma vez que são sistematicamente utilizados para gerar novos discursos que defendem o autor e legitimam novamente sua imagem celebrada. Em outros termos, criam-se, desse modo, duas principais representações quanto à identidade do autor Ziraldo nesse espaço: um herói celebrado e um vilão hostilizado.

\section{À guisa de conclusão}

As principais representações em torno das identidades de um autor literário, no Ocidente, têm sido constituídas tradicionalmente no âmbito governado pela cultura escrita impressa, como nos demonstram, entre outros, os estudos realizados por Roger Chartier. Desde o século XVIII, o espaço privilegiado para a construção dos 
discursos legitimados sobre a literatura tem sido a Crítica Literária. Hoje, essa construção é ampliada pela utilização do ciberespaço como meio de divulgação, discussão e, sobretudo, construção de novas identidades de autor. A Internet, nesse sentido, pode fortalecer representações e discursos antigos, mas também é capaz de gerar novas possibilidades de representar o autor literário.

Na medida em que entra na ordem dos discursos que circulam no espaço de uma comunidade do Orkut, o nome de Ziraldo passa a ser construído de uma forma dicotômica e polarizada, beirando, em alguns casos, as figuras caricatas do herói e do vilão televisivo. De fato, essas figuras amplamente divulgadas pela cultura da mídia parecem constituir a referência, nesse espaço, para realizar juízos e construir comentários, em parte, devido ao modo como os próprios moderadores preconizam discursos celebratórios.

Entre os discursos que idolatram o autor, encontramos representações de Ziraldo enquanto um artista genial, uma figura de relevância política em nosso país, além de um grande educador e representante legítimo do que a cultura brasileira possui de melhor e mais elaborado. Já entre os discursos que o vilipendiam, percebe-se que Ziraldo é representado como um capitalista inescrupuloso - no sentido de que utilizaria a sua arte como um produto de consumo voltado para as massas, com o fim único de ganhar dinheiro; um oportunista - pois teria usado a fama para receber indenização do governo; e um elitista esnobe - devido às suas declarações não favoráveis à variação linguística usada na Internet.

Para concluir, pode-se afirmar que o modo como as representações do autor Ziraldo se transformam, na medida em que se deslocam do âmbito da Crítica Literária para a internet, expõe o caráter "produzido" de toda identidade. Por isso mesmo, não é possível fixar qualquer noção única de identidade autoral. Se é verdade que transformações e deslocamentos quanto a essa identidade são comuns ao longo da história - como nos demonstram, entre outros, os estudos de Foucault e Chartier -, também é verdade que, no ciberespaço, identidades 
aparentemente fixas são tomadas por uma instabilidade incomum em outros âmbitos da cultura escrita.

A internet, enquanto um meio relativamente isento de mediações, submete a identidade do autor a uma pluralização e uma fragmentação de representações tamanha que permite visualizar, talvez de modo exemplar, aquilo que Stuart Hall (1997) denominou de 'crise de identidade', no sentido de que o panorama cultural contemporâneo constitui-se de múltiplas possibilidades, cruzamentos, entrelaçamentos. Por isso mesmo, não é possível falar em um padrão fechado para as identidades, puro, fixo ou estável, pois elas se constroem a todo momento nas redes sociais, nos desejos e nos sonhos dos indivíduos.

\section{Referências}

ABDALA, Benjamin Jr.; CAMPEDELLI, Samira Yousesef. Ziraldo: seleção de textos, notas, estudos biográfico, histórico e crítico e exercícios. São Paulo: Abril Educação, 1982.

CHARTIER, Roger. A aventura do livro: do leitor ao navegador. São Paulo: Editora UNESP, 1998.

Cultura escrita, literatura e história: conversas de Roger Chartier com Carlos Aguirre Anaya, Jesús Anaya Rosique, Daniel Goldin e Antonio Saborit. Porto Alegre: ARTMED Editora, 2001.

. Os desafios da escrita. São Paulo: Editora UNESP, 2002.

UNESP, 2007.

Inscrever e apagar: cultura escrita e literatura. São Paulo: Editora

COELHO, Nelly Novaes. A literatura infantil: história, teoria, análise. São Paulo: Quíron, 1987. 
COSTA, Marisa Vorraber. Estudos Culturais e educação - um panorama. In: SILVEIRA, Rosa Maria Hessel (Org.). Cultura poder e educação: um debate sobre os estudos culturais em educação. Canoas: Ed. ULBRA, 2005.

FOUCAULT, Michel. O que é um autor? 6. ed. Lisboa: Nova Vega, 2006.

HALL, Stuart. A identidade cultural na pós-modernidade. Rio de Janeiro: DP\&A, 1997.

(Org.). Representation. Cultural representation and signifying practices. Sage/Open University: London/Thousand Oaks/New Delhi, 1997.

KIRCHOF, Edgar Roberto. O desaparecimento do autor nas tramas da literatura digital: uma reflexão foucaultiana. In: Signo. Santa Cruz do Sul, v. 34, n. 56, p.4763, jan./jun. 2009. Disponível em: $<$ http://online.unisc.br/seer/index.php/signo/article/view/962>. Acesso em: 05 de dezembro de 2009.

LAJOLO, Marisa; ZILBERMAN, Regina. Literatura Infantil brasileira: histórias e histórias. São Paulo: Ática, 2002.

MOISÉS, Maussaud. Dicionário de termos literários. São Paulo: Cultrix, 2004.

MOREIRA, Antonio Flávio Barbosa. Currículo e Estudos Culturais: tensões e desafios em torno das identidades. SILVEIRA, Rosa Maria Hessel (Org.). Cultura, poder e educação: um debate sobre os estudos culturais em educação. Canoas: Ed. ULBRA, 2005.

SILVA, Thomaz Tadeu da. A produção social da identidade e da diferença. In: SILVA, Tomaz Tadeu da (Org.). Identidade e diferença: a perspectiva dos estudos culturais. Petrópolis, RJ: Vozes, 2007.

SILVEIRA, Rosa Maria Hessel. Identidades para serem exibidas: breve ensaio sobre o Orkut. In: SOMMER, Luís Henrique; BUJES, Maria Isabel Edelweiss (Org.). Educação e cultura contemporânea: articulações, provocações e transgressões em novas paisagens. Canoas: Ed. ULBRA, 2006. 
WOODWARD, Kathryn. Identidade e diferença: uma introdução teórica e conceitual. In: SILVA, Tomás Tadeu da. Identidade e diferença: a perspectiva dos Estudos Culturais. Petrópolis: Vozes, 2006. p. 7-72.

ZILBERMAN, Regina. A literatura infantil na escola. São Paulo: Global, 1994.

ZIRALDO. O menino maluquinho. São Paulo: Melhoramentos, 1980.

2009.

Flicts. Edição Comemorativa 40 anos. São Paulo: Melhoramentos, 